\title{
On the presence of hepatic stellate cells in portal spaces
}

\section{Yánnick de O liveira Fonseca, Camila Bião Lima, Elisângela Trindade Santos, Zilton A Andrade ${ }^{+}$}

\author{
Laboratório de Patologia Experimental, Centro de Pesquisas Gonçalo Moniz-Fiocruz, Rua Valdemar Falcão 121, \\ 40295-001 Salvador BA, Brasil
}

Previous studies in mice with hypervitaminosis A have demonstrated that fat-storing cells (hepatic stellate cellsHSCs) participate in schistosomal granuloma fibrogenesis. The origin of such cells in portal areas, away from the Disse spaces, was herein investigated. HSCs were identified in frozen sections of the liver by means of Sudan III staining. They appeared as red-stained cells disposed along the sinusoids of normal mice, but were never found within portal spaces. However, in the chronically inflamed portal spaces of Capillaria hepatica-infected mice, Sudan III-positive cells were frequently present among leukocytes and fibroblast-like cells. Thus, there are no resident HSCs in portal spaces, but their presence there in chronic inflammatory processes indicates that they are able to migrate from peri-sinusoidal areas in order to reach the portal areas.

Keywords: hepatic stelate cells - portal fibrosis - portal myofibroblasts

Hepatic stellate-cells (HSCs), also known as fat-storing cells and Ito cells, are considered the main cellular factor of hepatic fibrogenesis. They are residents of the parasinusoidal spaces (Disse spaces), and can be identified by their star-shaped form, and by the presence of characteristic fat-droplets in the cytoplasm. At the time they become engaged in fibrogenesis, they lose the cytoplasmic fat droplets and assume a myofibroblas/fibroblast phenotype (Friedman 2000, Geerts 2001).

The reason for the present research note derives from a previous investigation by Barbosa et al. (1993). They searched for the presence of HSCs within the periovular granulomas of experimental schistosomiasis of mice. Their aims were to find out whether HSCs would participate in the genesis of fibrosis in schistosomal periovular granuloma, a portal rather than a parenchymal lesion. Fibroblast-like fat-storing cells were then demonstrated within the granulomas formed in the liver of mice previously treated with high doses of Vitamin A. However, two questions were argued and not answered at that time: are cells with fat-storing potential normally present in portal spaces? If not, can HSCs really migrate to portal spaces during chronic inflammation? The findings of experimental schistosomiasis suggested this latter alternative as the most plausible.

To further investigate this matter, the following experimental procedures were performed. Twenty Wistar female rats, weighing 180-200 g, maintained in air-conditioned room $\left(21-22^{\circ} \mathrm{C}\right)$, with free access to a commercial balanced diet and water, were randomly separated into

Finacial support: Papes III, Pronex

${ }^{+}$Corresponding autor. E-mail: zilton@cpqgm.fiocruz.br Received 3 January 2005

Accepted 28 March 2005 four groups of 5 animals each. The first 5 animals were treated with subcutaneous injections of Vitamin A (retinol palmitate - Arovit, Roche), administered in the dose of $50,000 \mathrm{IU}(0.16 \mathrm{ml})$ twice a week, performing the total dose of 400,000 IU in a treatment lasting for four weeks. The other group of 5 animals were previously infected with 500 mature eggs of Capillaria hepatica (see technical details in Andrade \& Andrade 2004) and submitted to treatment with Vitamin A, starting on the 11th day after inoculation, and following the same schedule and dose as for the preceding group. Two control groups of 5 animals each were added; one of intact animals treated with $0.85 \%$ saline, simulating all details of the treatment with Vitamin A; and another of $C$. hepatica-infected animals with saline replacing Vitamin A for the injections.

Fragments of the liver were collected by biopsy from all animals on the 32 nd day from $C$. hepatica infection, and by autopsy 22 days later when all the animals were anesthetized and exsanguinated. Small pieces of the liver were immediately frozen in liquid nitrogen, stored in a $-70^{\circ} \mathrm{C}$ freezer, until they were cut in a cryostat. Sections were fixed in acetone and stained with Sudan III and lightly counterstained with hematoxylin. Other fragments were fixed in buffered formalin, embedded in paraffin and routinely stained with hematoxylin and eosin, Sirius-red for collagen, the Perls' method for iron, and PAS, with or without previous diastase treatment.

Treatment of normal rats with Vitamin A caused HSCs to be stuffed with large cytoplasmic fat droplets, turning them easily detected under the low power of the light microscope, when stained with Sudan III (Fig. 1A, B). These fat-storing cells were always observed in peri-sinusoidal location, not in portal spaces, even when some extra mesenchymal cells were present there (Fig. 1B).

C. hepatica-infected animals presented scattered focal parasitic hepatic lesions, with dead worms and collections of eggs, besides portal infiltration by leucocytes, 

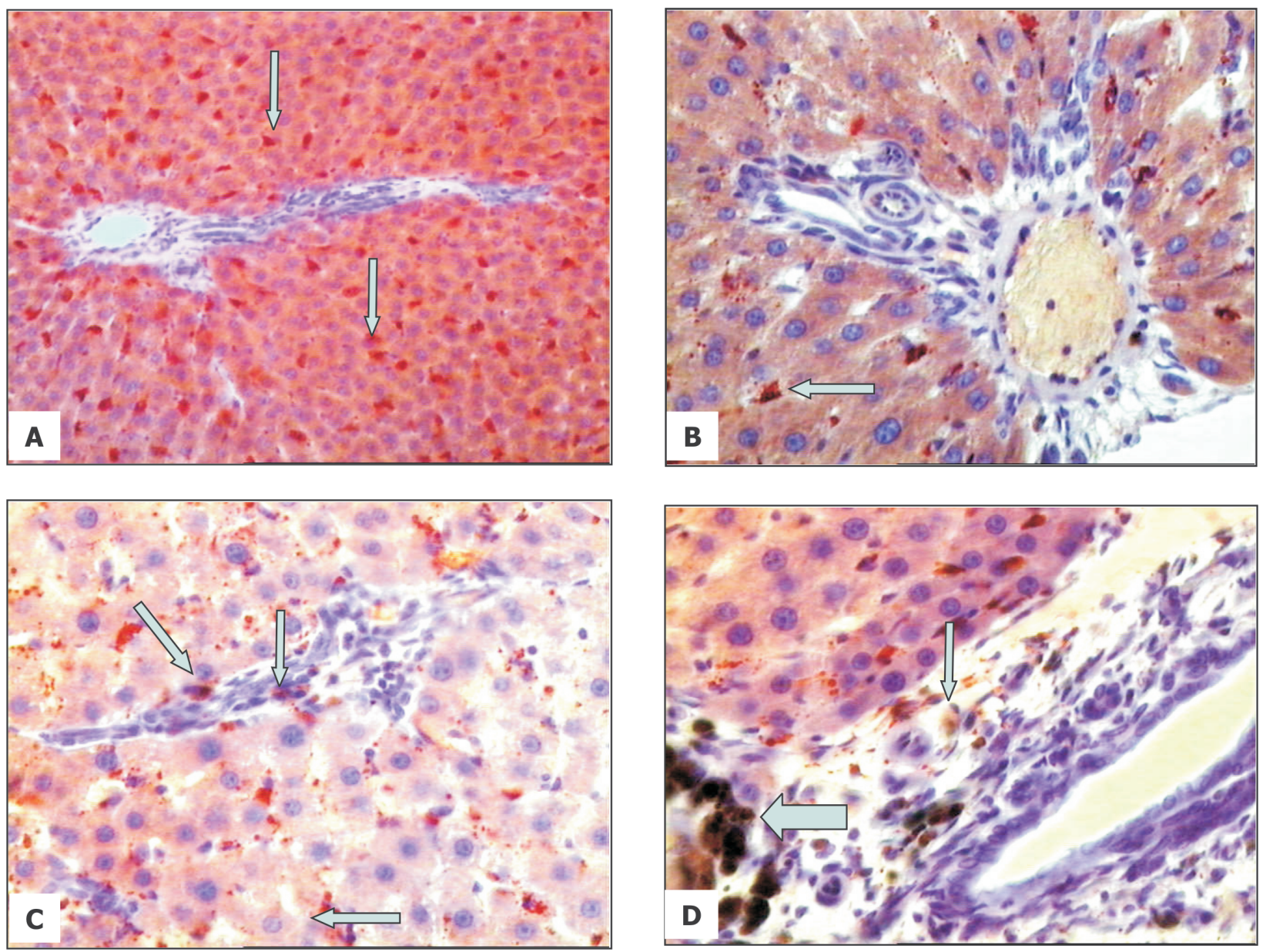

Fig. 1 A, B: frozen sections from the liver of normal mice stained with Sudan III reveal red-stained fat-storing cells (arrows) disposed along the hepatic sinusoids, but portal spaces are devoid of such cells. A 100x; B 400x; C, D: several fat-storing cells (arrows) appear within the mildly inflamed portal spaces of Capillaria hepatica-infected mice. In D it can be noted a clump of large dark-stained cells (large arrow), which represent lipid-laden macrophages frequently found in liver sections from C. hepatica-infected animals. C 200x; D 400x.

and systematized septal fibrosis, as previously described (Ferreira \& Andrade 1993, Andrade \& Andrade 2004). When treated with Vitamin A they exhibited fat-storing cells (Sudan III-positive) not only in peri-sinusoidal areas, but also in portal spaces, and along areas of septal fibrosis (Fig. 1C, D). These Sudan III-positive cells found within the hepatic fibrous tissues were to be differentiated from lipid-laden macrophages, common in C. hepatica lesions, which appear as dark large cells, with iron-containing pigment and PAS-positive-distase-resistant lipid material (Fig. 1D, arrow).

To answer the specific question posed by the present research, the positive identification of HSCs in tissue sections represented a crucial problem, since such cells usually loose their cytoplasmic fat droplets when involved in fibrogenesis. Immuno-histochemistry proved of little avail. Desmin and smooth-muscle actin are indeed expressed by HSCs, but several other cells present in portal chronic inflammatory lesions also do the same (Barbosa et al. 1993).
On the other hand, it has been demonstrated that there are many desmin-negative Ito cells in normal liver (Ballardini et al. 1994). Fortunately, pre-treatment of the animals with excess Vitamin A revealed to be a fair alternative. It caused HSCs to be distended with large lipid droplets and thus easily recognized under the low power of the light microscope. Even after transformation into myofibroblasts and fibroblasts the demonstration of cytoplasmic fat droplets is still possible to be made by electron microscopy, denouncing their origin from HSCs, as observed during the studies with schistosomiasis (Barbosa et al. 1993). Cassiman et al. (2002) called attention to myofibroblasts as normal residents of portal spaces. Besides, in pathological conditions they can also derive from periductal pericytes (Rosmoduc et al. 1999), and from vascular smooth muscle, as demonstrated in human schistosomal periportal fibrosis (Andrade et al 1999). Of course portal myofibroblats can also be derived from HSCs. Present findings support that possibility. 


\section{REFERENCES}

Andrade SB, Andrade ZA 2004. Experimental hepatic fibrosis due to Capillaria hepatica infection (Differential features presented by rats and mice). Mem Inst Oswaldo Cruz 99: 399-406.

Andrade ZA, Guerret S, Fernandes AL 1999. Myofibroblasts in schistosomal portal fibrosis of man. Mem Inst Oswaldo Cruz, 94: 87-93.

Ballardini G, Groff P, Badiali LG, Schuppan D, Bianchi FB 1994. Ito cell heterogeneity: desmin-negative Ito cells in normal rat liver. Hepatology 19: 440-446.

Barbosa Jr AA, Pfeiffer U, Andrade ZA 1993. Role of fatstoring cells (FSC) in schistosomal hepatic fibrosis of mice. Virchow's Arch B 64: 91-96.
Cassiman D, Libbrecht L, Desmet V, Denef C, Roskmans T 2002. Hepstic stellate cell/myofibroblast subpopulations in fibrotic human and rat livers. J Hepatol 36: 200-209.

Friedman SL 2000. Molecular regulation of hepatic fibrosis, an integrated cellular response to tissue injury. $\mathrm{J} \mathrm{Biol} \mathrm{Chem}$ 275: 2247-2250.

Geerts A 2001. History, heterogeneity, developmental biology, and functions of quiescent hepatic stellate cells. Sem Liver Dis 21: 311-335.

Rosmorduc O, Wendum D, Corpechot C, Galy B, Sebbag N, Raleigh J, Housset C, Poupon R. 1999. Hepatocellular hypoxia-induced vascular endothelial growth factor expression and angiogenesis in experimental biliary cirrhosis. Am J Pathol 155: 1065-1073. 
